\title{
Type 1 Diabetes Mellitus and Cognitive Impairments: A Systematic Review
}

\author{
Wei Li ${ }^{1}$, Edgar Huang ${ }^{2}$, Sujuan $\mathrm{Gao}^{3}$ \\ ${ }^{1}$ Master of Physician Assistant Studies, School of Health and Rehabilitation Sciences, \\ Indiana University-Purdue University Indianapolis, Indianapolis, Indiana \\ ${ }^{2}$ School of Informatics and Computing, Indiana University-Purdue \\ University Indianapolis, Indianapolis, Indiana \\ ${ }^{3}$ Department of Biostatistics, School of Medicine, Indiana University, Indianapolis, \\ Indiana
}

Running Title: T1DM and Cognitive Impairments

Word count (abstract): 222

Keywords: Cognitive Impairments, Diabetic Ketoacidosis (DKA), Microangiopathy, Severe Hypoglycemia (SH), Type 1 Diabetes Mellitus (T1DM)

Correspondence:

Dr. Wei Li

Master of Physician Assistant Studies

School of Health \& Rehabilitation Sciences

Indiana University Purdue University Indianapolis

2039 N. Capitol Avenue, Indianapolis, IN 46202

Phone: 317-278-9575

Fax: 317-278-9555

Email:wl23@iu.edu 


\section{AUTHOR CONTRIBUTIONS}

Wei Li led the study concept and design. All authors contributed to content, draft and critical revisions of the manuscript. 


\begin{abstract}
Type 1 diabetes mellitus (T1DM) is a major subtype of diabetes and is usually diagnosed at a young age with insulin deficiency. The life expectancy of T1DM patients have increased substantially in comparison with that three decades ago due to the availability of exogenous insulin, though it is still shorter than that of healthy people. However, the relation remains unclear between T1DM and dementia as an agingrelated disease. We conducted a systematic review of existing literature on T1DM and cognition impairments by carrying out searches in electronic databases Medline, EMBASE, and Google Scholar. We restricted our review to studies involving only human subjects and excluded studies on type 2 diabetes mellitus or non-classified diabetes. A meta-analysis was first performed on the relationship between T1DM and cognitive changes in youths and adults respectively. Then the review focused on the cognitive complications of T1DM and their relation with the characteristics of T1DM, glycemic control, diabetic complications, comorbidities, and others. First, age at onset, disease duration, and glycemic dysregulation were delineated for their association with cognitive changes. Then diabetic ketoacidosis (DKA), angiopathy, and neuropathy were examined as diabetic complications for their involvement in cognitive impairments. Lastly, body mass index and blood pressure were discussed for their relations with the cognitive changes. Future studies are needed to elucidate the pathogenesis of T1DMrelated cognitive impairments or dementia.
\end{abstract}




\section{Introduction: T1DM and the Risk of Dementia}

As a major subtype of diabetes, type 1 diabetes mellitus (T1DM) accounts for about $5 \%$ of all diabetic cases [1]. The main feature of T1DM is insulin deficiency, and patients with T1DM are treated with different types of exogenous insulin (rapid-, short-, intermediate-, and long-acting insulin). Thus, T1DM is also called insulin-dependent diabetes mellitus (IDDM).

Although their life span expectancy is still shorter than that of healthy people, T1DM patients now live much longer than they did three decades ago due to the availability of exogenous insulin [2, 3]; the prolonged life span thus makes them at risk for the agingrelated disease: dementia. In one retrospective study, the risk ratio for dementia in hospital-admitted T1DM patients was 1.65 times over the non-diabetic controls [4]. However, the study sample is not representative of the T1DM patient population as most T1DM patients are on an outpatient insulin treatment plan. Therefore, how T1DM is related to dementia or cognitive impairments is an unanswered question for T1DM patients and healthcare providers.

We conducted a systemic review by searching the electronic databases Medline, EMBASE, and Google Scholar with the following keywords: type 1 diabetes, insulindependent diabetes mellitus, cognitive impairment, and dementia. After removing duplicates and review articles, the original search returned a total of 310 results. After

the abstracts were examined, 215 studies were excluded from further analysis as they were either totally irrelevant $(n=135)$ or on type 2 diabetes mellitus $(n=38)$, animal models $(n=13)$, or non-classified diabetes $(n=29)$. The current review has focused on the 59 original reports published on or after the year of 1990 from the remaining studies 
$(n=95)$.

\section{Cognitive Changes in T1DM Patients}

Cognitive impairments refer a continuum of severity from "mild," which might be noticed by the patient or healthcare providers to "severe," such as dementia, which interferes with activities of daily life or disallows a patient to function without assistance. As age is an important factor for cognitive impairments, cognitive changes were reviewed separately in young or adult T1DM patients based on their age at the time of neuorpsychological assessments. For young T1DM patients, the cognitive function or performance is presented in Table 1. Impaired executive functions [5] and motor speed task [6] are seen in young T1DM patients between 9 years old and 19 years old (Table 1). In another study, a worse performance on visual-spatial ability and memory is shown in pediatric T1DM patients than the control group [7]. In addition, lower verbal intelligence is observed in the young T1DM group than the non-diabetic control group $[8,9]$ (Table 1). However, the association between T1DM and impaired cognitive functions has not been observed in other studies. For example, no significant difference was found from a prospective study between young adults with early-onset T1DM and controls in general intellectual ability, memory, and emotional difficulties [10] (Table 1). Although students with T1DM had a significantly lower academic performance than their non-diabetic classmates [11] (Table 1), they and their unaffected siblings had no significant differences on measures of cognitive performance, academic achievement, or speech ability [12] (Table 1).

For adult T1DM patients, cognitive impairments were consistently reported from 
different studies $[13,14,15]$ (Table 2 ). In one study, the incidence rate of cognitive impairments was $28 \%$ among adult patients with childhood-onset T1DM compared to the $5 \%$ in those without diabetes, though the study had a relatively small sample size and only included T1DM cases with a childhood-onset [14]. Different types of cognitive functions are impaired in adult patients with T1DM. For example, the adult T1DM patients have a worse performance in memory than nondiabetic controls [16] (Table 2).

\begin{tabular}{|c|c|c|c|c|c|c|}
\hline $\begin{array}{l}\text { Study } \\
\text { Design }\end{array}$ & $\begin{array}{l}\text { T1DM } \\
\text { Patient Age } \\
\text { (years) }\end{array}$ & $\begin{array}{l}\text { Sample } \\
\text { Size } \\
\text { (n) }\end{array}$ & $\begin{array}{l}\text { Cognitive Function } \\
\text { Changes versus } \\
\text { Controls }\end{array}$ & $\begin{array}{l}\text { Age at } \\
\text { Onset } \\
\text { (years) }\end{array}$ & $\begin{array}{l}\text { Disease } \\
\text { Duration } \\
\text { (years) }\end{array}$ & References \\
\hline Case-control & $(9-19)$ & 70 & $\begin{array}{l}\text { Impaired executive } \\
\text { functions: concept } \\
\text { formation, cognitive } \\
\text { flexibility, and } \\
\text { anticipation }\end{array}$ & $\begin{array}{l}<6 \\
(n=13) ; \geq 6 \\
(n=55)\end{array}$ & $0.9-13.7$ & [5] \\
\hline Case-control & $(9-18)$ & 25 & $\begin{array}{l}\text { Impaired motor speed } \\
\text { task }\end{array}$ & & & [6] \\
\hline Case-control & $(4-16)$ & 119 & $\begin{array}{l}\text { Worse visual-spatial } \\
\text { ability and memory }\end{array}$ & & $\geq 2$ & [7] \\
\hline $\begin{array}{l}\text { Cross- } \\
\text { sectional }\end{array}$ & $\begin{array}{l}16.2 \pm 3.1 \\
(9-22)\end{array}$ & 61 & Lower verbal intelligence & $\begin{array}{l}6.7 \pm 2.9 \\
(1-13)\end{array}$ & $\begin{array}{l}9.4 \pm 2.6 \\
(5-17.7)\end{array}$ & [8] \\
\hline Case-control & $12.1 \pm 2.9$ & 117 & Lower verbal intelligence & $6.8 \pm 3.3$ & $\geq 2$ & [9] \\
\hline $\begin{array}{l}\text { Prospective } \\
\text { Cohort }\end{array}$ & $19.3 \pm 0.5$ & 33 & No significant changes & $3.3 \pm 0.3$ & $16.0 \pm 0.5$ & [10] \\
\hline $\begin{array}{l}\text { Cross- } \\
\text { sectional }\end{array}$ & $\begin{array}{l}17.0 \pm 0.5 \\
(14.2-19.4)\end{array}$ & 36 & $\begin{array}{l}\text { Lower academic } \\
\text { performance }\end{array}$ & & $6.1 \pm 0.7$ & [11] \\
\hline Case-control & $12.4 \pm 3.0$ & 27 & No significant difference & $<5$ & & [12] \\
\hline
\end{tabular}




\begin{tabular}{|l|l|l|l|l|l|l|}
\hline & (6-20) & $\begin{array}{l}\text { in academic } \\
\text { performance or cognitive } \\
\text { functions }\end{array}$ & & & \\
\hline
\end{tabular}

Table 1. Cognitive function changes were studied in children/young adults ( $\leq 22$ years old) with T1DM. Patient age, age at onset of T1DM, and disease duration are presented as mean \pm standard deviation followed by range in years.

\begin{tabular}{|c|c|c|c|c|c|c|}
\hline Study Design & $\begin{array}{l}\text { T1DM } \\
\text { Patient Age } \\
\text { (years) }\end{array}$ & $\begin{array}{l}\text { Sample } \\
\text { Size }(n)\end{array}$ & $\begin{array}{l}\text { Cognitive Function } \\
\text { Changes versus } \\
\text { Controls }\end{array}$ & $\begin{array}{l}\text { Age at } \\
\text { onset } \\
\text { (years) }\end{array}$ & $\begin{array}{l}\text { Disease } \\
\text { Duration } \\
\text { (years) }\end{array}$ & References \\
\hline $\begin{array}{l}\text { Cross- } \\
\text { sectional }\end{array}$ & $43.3 \pm 7.8$ & 150 & $\begin{array}{l}\text { Cognitive } \\
\text { impairment }\end{array}$ & $17.2 \pm 11.2$ & $26.6 \pm 11.4$ & [13] \\
\hline Case-control & $49.1 \pm 6.6$ & 97 & $\begin{array}{l}\text { Cognitive } \\
\text { impairment }\end{array}$ & $8.0 \pm 4.2$ & $41.0 \pm 6.2$ & [14] \\
\hline Case-control & $39.2 \pm 6.7$ & 55 & $\begin{array}{l}\text { Cognitive } \\
\text { impairment }\end{array}$ & & $(6-35)$ & [15] \\
\hline $\begin{array}{l}\text { Cross- } \\
\text { sectional }\end{array}$ & $32.3 \pm 4.4$ & 123 & $\begin{array}{l}\text { Lower performance } \\
\text { in memory, } \\
\text { executive function, } \\
\text { and psychomotor } \\
\text { speed }\end{array}$ & $12.5 \pm 5.2$ & $19.9 \pm 3.5$ & [16] \\
\hline Case-control & $40.4 \pm 6.2$ & 103 & $\begin{array}{l}\text { Decreased } \\
\text { psychomotor } \\
\text { efficiency }\end{array}$ & $8.9 \pm 3.9$ & $31.5 \pm 7.0$ & [17] \\
\hline Case-control & $43.4 \pm 1.1$ & 122 & $\begin{array}{l}\text { Impaired sustained } \\
\text { attention }\end{array}$ & $18.2 \pm 1.0$ & $25.4 \pm 1.0$ & [18] \\
\hline
\end{tabular}




\begin{tabular}{|l|l|l|l|l|l|l|}
\hline Case-control & $60.9 \pm 6.0$ & 40 & Slower information & $\leq 18$ & $34.0 \pm 12.8$ & [19] \\
& & & processing speed & $(n=14) ;>$ \\
& & & & \\
& & & & & \\
& & & & & \\
\hline
\end{tabular}

Table 2. Cognitive function changes were studied in adult patients ( $>22$ years old) with T1DM. Patient age, age at onset of T1DM, and disease duration are presented as mean \pm standard deviation followed by range in years.

In addition, adult T1DM patients have significantly reduced psychomotor efficiency [16, 17], sustained attention [18], and information processing speed [19] (Table 2). Lastly, adult patients with T1DM have impaired executive functions in concept formation, cognitive flexibility, and anticipation [16] (Table 2).

\section{Age at Onset, Disease Duration, and Cognitive Impairments}

T1DM usually has an early age at onset (AAO) and is most often diagnosed in children and young adults; therefore, T1DM is also called juvenile diabetes. The developing brain might be more vulnerable to the effects of dysglycemia in young T1DM patients [20]. The AAO is an important characteristic of T1DM for influencing cognitive functions in patients with T1DM. A worse cognitive performance is usually associated with an earlier AAO. For example, learning and memory skills are more affected in pediatric T1DM patients with early onset than those with late onset [21]. Pathologically, more atrophic cerebral structural changes are found in early-onset than in late-onset young T1DM patients. Moreover, the medial prefrontal regions, insula, and cerebellum are the known rapidly developing brain regions in children, which are significantly affected by 
the early-onset T1DM [22]. These structural changes of decreased gray matter volume might have long-term effects on cognitive functions.

Similarly, current intellectual ability and information processing ability are poorer in young adults with early-onset T1DM ( $<7$ years old) than those with late-onset ( $7-17$ years old) T1DM [23]. The fact that central brain atrophy in the early-onset T1DM group is more prevalent than that in the late-onset T1DM group suggests that the structural changes are the underlying reason for the different cognitive performance between the two groups. Further, the neurodevelopment in children may be affected by early-onset diabetes, which might have long-term deteriorating effects on cognition [23].

Disease duration is another important characteristic of T1DM, which is inversely associated with cognitive performance. Together with $\mathrm{AAO}$, disease duration has been reported to be the strong predictors for impaired cognition functions in psychomotor speed, memory, processing speed, attention, working memory, verbal ability, general intelligence, and executive function in adult T1DM patients [13]. In addition, a delayed recall task performance is inversely related to the disease duration [24]. Moreover, disease duration could effectively predict the psychomotor speed decline in adult patients with T1DM [17]. However, the relationship between disease duration and cognitive changes has to be analyzed by taking into consideration the age factor. Not surprisingly, cognitive impairments in adolescent T1DM patients were reported to be independent of both glycemic control and disease duration in one study [5], and the finding suggested that T1DM might have direct pathological effects on cognitive functions. 


\section{Glycemic Control in Patients with T1DM}

Although different types of exogenous insulin are available for optimizing glycemic control, T1DM patients could not regulate their glucose metabolism as effectively as a healthy person can do with the endogenous insulin. Ironically, insulin therapy itself is associated with conditions of either hyperglycemia or hypoglycemia [25]. For example, insulin treatment is shown to be associated with the incidence rate of hypoglycemia in pediatric T1DM patients (9-15 years old) [26]. In addition, the glycemic control usually deteriorates along with the increasing duration of T1DM [5]. Thus, either hyperglycemia or hypoglycemia or both are commonly seen in patients with T1DM.

\section{Hyperglycemia and Cognitive Changes}

Hyperglycemia can be either chronic or induced acutely by using experimental technologies [27]. Chronic hyperglycemia is shown to be associated with low general cognitive abilities, slow fine motor speed, and low receptive language function among pediatric T1DM patients ( $<6$ years old) [28]. Spelling performance is also reduced in the youth with T1DM with increased exposure to chronic hyperglycemia in terms of disease duration and level of hyperglycemia [8]. In adult T1DM patients, poor performance on psychomotor task, slow mental subtraction speed, and increased subtraction errors are seen as the effects of acute hyperglycemia when the blood glucose is above $15 \mathrm{mmol} / \mathrm{L}$ [29]. In addition, among middle-aged participants with T1DM, cognitive impairments are associated with chronic hyperglycemia [14]. Although most studies have shown that the chronic hyperglycemia is associated with the cognitive changes in T1DM patients, the 
same relationship is not observed on the long-term spatial memory performance in children with T1DM (6-18 years old) [30].

It is worthy to note that AAO may interact with hyperglycemia for influencing cognitive functions in T1DM patients. For instance, hyperglycemia is negatively correlated with visual-spatial ability in young T1DM patients, and the correlation is stronger in these patients with an early AAO than in those with late AAO [7]. The level of hyperglycemia is another important factor for influencing cognitive functions. For instance, the level of hyperglycemia is negatively associated with intelligence and information processing speed in pediatric T1DM patients [7]. In addition, a higher HbA1c at T1DM diagnosis in young patients (7-17 years old) is associated with a worse performance on the longdelay spatial delayed response task [31] as well as lower psychomotor and mental efficiency in adolescents (13-19 years old) [32]. Even an acute hyperglycemia achieved with a modified clamp technique is associated with impaired complex cognitive function in children with T1DM [27]. When blood glucose is in the $20-$ to $30-\mathrm{mmol} / \mathrm{l}$ range, the children's intelligence quotient is reduced by $9.5 \%$. Also, $\mathrm{HbA} 1 \mathrm{c}$ values are negatively associated with declines in motor speed and psychomotor efficiency, according to another study that involved a mixed age group of T1DM patients (13-39 years old [33]). Therefore, the effects of chronic hyperglycemia on cognitive performance are associated with the AAO of T1DM, T1DM duration or both.

\section{Hypoglycemia and Cognitive Functions}

Hypoglycemia, another condition commonly seen in T1DM patients, has been studied for its relationship with cognitive changes as well. Attention flexibility [34], spatial ability 
[35], and speed of information processing [34] are impaired with hypoglycemia. Early visual information processing and contrast sensitivity are also impaired during hypoglycemia in adult T1DM patients [36]. In addition, psychomotor speed and reaction speed are significantly decreased during hypoglycemic episodes (based on home blood glucose readings) for school-aged children [37]. Besides the AAO, frequency of hypoglycemia seems to play an important role in the cognitive changes seen in T1DM patients. For instance, spatial intelligence and delayed recall are reduced only with repeated hypoglycemic episodes, particularly when those hypoglycemic episodes occur before the age of 5 [9]. However, the association between hypoglycemia and cognitive impairments has not been observed in other reports. For example, verbal intelligence is not lowered by increased exposure to hypoglycemia in young T1DM patients (5-17 years old) [9], and the number of prior hypoglycemic events is not associated with any changes in the cognitive functions in adult T1DM patients [13]. Moreover, sustained attention and intelligence are preserved during hypoglycemia induced with a hyperinsulineamic glucose clamp in adult T1DM patients [34].

\section{Severe Hypoglycemia (SH) and Cognitive Functions}

As the most serious side effect of insulin therapy, severe hypoglycemia ( $\mathrm{SH}$ ) affects 30$40 \%$ of T1DM patients $[33,38]$. The risk of contracting $\mathrm{SH}$ increases with unawareness of hypoglycemia as well as increased glucose variability in adult patients with longstanding T1DM [45]. SH is defined as having low blood glucose level that requires the help of others for the treatment. In addition, patients with concurrent hypoglycemia ( $<70$ $\mathrm{mg} / \mathrm{dL}$ but $\geq 40 \mathrm{mg} / \mathrm{dL}$ ) and coma or seizure are also classified as having $\mathrm{SH}$ (10). The 
association between $\mathrm{SH}$ and cognitive function changes has not been observed in young T1DM patients. For instance, a history of $\mathrm{SH}$ is not associated with the cognitive decrements in a T1DM patient group between 13 years old and 39 years old in a longitudinal study [39]. Moreover, $\mathrm{SH}$ is not associated with changes in either academic abilities [8, 21] or any other cognitive functions in children with T1DM [40]. Furthermore, it is still debatable how frequency of $\mathrm{SH}$ and $\mathrm{AAO}$ affect the cognitive functions in T1DM patients (33). For example, children with a SH history have more neuropsychological impairments than those without it [41]. In addition, high frequency of and early exposure to $\mathrm{SH}$ in children with T1DM negatively affect spatial long-term memory performance [9, 30]. Nevertheless, one study reports that $\mathrm{SH}$ does not cause cognitive dysfunction in children even with severe hypoglycemia occurring during early childhood ( $<6$ years old) [42]. By contrast, type 1 diabetic patients with recurrent $\mathrm{SH}$ are shown to have worse cognitive functions than those without a history of SH [43, 44].

\section{DKA and Cognitive Functions}

Diabetic ketoacidosis (DKA) is a very serious complication of T1DM that can lead to coma or death. This condition happens when the body does not have enough insulin for regulating glucose metabolism and when increased ketone production leads to metabolic acidosis. The prevalence rate of DKA varies from $20.9 \%$ to $75 \%$ in newly diagnosed T1DM patients, and the average rate is 38.8\% [46-53]. The DKA is shown to be a risk factor for cognitive impairments in patients with T1DM. Pediatric patients with newly diagnosed T1DM and DKA show a definite trend for having worse cognitive functions than the age-matched T1DM patients without DKA [54]. For example, young 
T1DM patients with DKA at the time of diabetes diagnosis perform worse on the spatial delayed response task than their non-diabetic sibling controls [31]. A history of DKA is also correlated with lower verbal intelligence quotient in children with T1DM [55]. In addition, these patients perform poorly on measures of executive function when they have a positive history of both DKA and hyperglycemia [55]. So the glycemic control is probably interacting with DKA to worsen the cognitive performance. However, a history of DKA is not associated with either decreased academic abilities or an increased risk of learning problems in children or young T1DM patients in other studies [8, 21]. The effects of DKA as well as its interaction with AAO, disease duration, and glycemic control are yet to be investigated.

\section{Angiopathy and Cognitive Functions}

Angiopathy in T1DM patients can be manifested as either microangiopathy or macroangiopathy or both. Retinopathy and nephropathy belong to microangiopathic complications of T1DM and are two common forms of diabetic microangiopathy, which has been suggested to be associated with cognitive impairments in patients with T1DM.

Besides hyperglycemia, retinopathy $[4,14]$ and nephropathy $[39,56]$ are independently associated with decrements in psychomotor efficiency. In addition, diabetic retinopathy is associated with poor cognitive performance on intelligence, information processing, and attention/concentration ability in adult T1DM patients [57]. However, it is still inconclusive whether microangiopathic complications are associated with cognitive impairments in T1DM patients. For example, the presence of retinopathy is not a significant predictor of poor cognitive performance in adult patients with T1DM [13]. 
Furthermore, microvascular complication status is not a relevant factor for cognitive impairments though adult T1DM patients perform poorer on general cognitive ability, information processing speed, and motor speed than the controls [58].

On the other hand, macrovascular health is associated with cognitive impairments in adult T1DM patients [14]. For instance, a decline in psychomotor speed can be predicted by macrovascular complications, duration of diabetes, proliferative retinopathy, and autonomic neuropathy [17].

\section{Other Factors}

Polyneuropathy is shown as the best biomedical predictor of cognitive performance in adult T1DM patients [59]. High body mass index (BMI) [13, 14] and hypertension [13] are shown as significant predictors of poor cognition functions in adult patients with T1DM. Specifically, systolic blood pressure can be used to predict the decline in psychomotor speed [17]. On the other hand, neither hypertension nor BMI are implicated in cognitive impairments of T1DM patients [39]. These studies are composed of T1DM patients who vary in age, age at onset of T1DM as well as disease duration. However, the discrepancy of these findings warrants further studies to examine hypertension's and BMl's roles in the cognitive changes of T1DM patients.

\section{Conclusion}

This review has focused on the cognitive impairments in young and adult T1DM patients. The cognitive changes have been examined from the following perspectives: AAO and duration of T1DM, glycemic dysregualtion, diabetic ketoacidosis (DKA), and 
angiopathy. In addition, other factors such as blood pressure, BMI, and neuropathy are discussed for their relations with the cognitive changes in T1DM patients. In children with T1DM, impaired cognitive functions or poor cognitive performance were observed in most studies (Table 1). In contrast, the impaired cognitive functions were seen more consistently in studies with adult T1DM patients (Table 2). Very few studies have a follow-up long enough to show whether poor cognitive performance and/or functions in childhood last into adulthood. However, some evidence $[22,23]$ has shown early-onset T1DM is associated with brain structural changes, which might have long-lasting effects on cognitive functions. However, prospective studies with a long follow-up design will be useful for investigating the long-term effects of early-onset T1DM on cognitive functions. In addition, future studies are needed to elucidate the underlying mechanism of T1DMrelated cognitive impairments or dementia.

\section{References}

1. www.cdc.gov/diabetes/basics/diabetes.html. Last updated March 31, 2015, Accessed on September 1, 2016.

2. Livingstone SJ, Levin D, Looker HC, Lindsay RS, Wild SH, Joss N, Leese G, Leslie P, McCrimmon RJ, Metcalfe W, McKnight JA, Morris AD, Pearson DW, Petrie JR, Philip S, Sattar NA, Traynor JP, Colhoun HM (2015) Estimated life expectancy in a Scottish cohort with type 1 diabetes, 2008-2010. JAMA 313, 37-44.

3. Miller RG, Secrest AM, Sharma RK, Songer TJ, Orchard TJ (2012) Improvements in the life expectancy of type 1 diabetes: the Pittsburgh Epidemiology of Diabetes Complications study cohort. Diabetes 61, 2987-2992. 
4. Smolina K, Wotton CJ, Goldacre MJ (2015) Risk of dementia in patients hospitalised with type 1 and type 2 diabetes in England, 1998-2011: a retrospective national record linkage cohort study. Diabetologia 58, 942-950.

5. Ohmann S, Popow C, Rami B, König M, Blaas S, Fliri C, Schober E (2010) Cognitive functions and glycemic control in children and adolescents with type 1 diabetes. Psychol Med 40, 95-103.

6. Hershey T, Bhargava N, Sadler M, White NH, Craft S (1999) Conventional versus intensive diabetes therapy in children with type 1 diabetes: effects on memory and motor speed. Diabetes Care 22, 1318-1324.

7. Kirchhoff BA, Jundt DK, Doty T, Hershey T. A longitudinal investigation of cognitive function in children and adolescents with type 1 diabetes mellitus. Pediatr Diabetes. 2016 Jul 22. doi: 10.1111/pedi.12414. [Epub ahead of print]

8. Semenkovich K, Patel PP, Pollock AB, Beach KA, Nelson S, Masterson JJ, Hershey T, Arbeláez AM (2016) Academic abilities and glycaemic control in children and young people with Type 1 diabetes mellitus. Diabet Med 33, 668-673.

9. Perantie DC, Lim A, Wu J, Weaver P, Warren SL, Sadler M, White NH, Hershey T (2008) Effects of prior hypoglycemia and hyperglycemia on cognition in children with type 1 diabetes mellitus. Pediatr Diabetes 9, 87-95.

10. Ly TT, Anderson M, McNamara KA, Davis EA, Jones TW (2011) Neurocognitive outcomes in young adults with early-onset type 1 diabetes: a prospective follow-up study. Diabetes Care 34, 2192-197.

11. Meo SA, Alkahlan MA, Al-Mubarak MA, Al-Obayli MS, Melaibary BA, Bin Dous AN, Alhassoun Al (2013) Impact of type 1 diabetes mellitus on academic performance. J Int 
Med Res 41, 855-858.

12. Crawford SG, Kaplan BJ, Field LL (1995) Absence of an association between insulin-dependent diabetes mellitus and developmental learning difficulties. Hereditas $122,73-78$.

13. Brismar T, Maurex L, Cooray G, Juntti-Berggren L, Lindström P, Ekberg K, Adner N, Andersson S (2007) Predictors of cognitive impairment in type 1 diabetes.

Psychoneuroendocrinology 32, 1041-1051.

14. Nunley KA, Rosano C, Ryan CM, Jennings JR, Aizenstein HJ, Zgibor JC, Costacou T, Boudreau RM, Miller R, Orchard TJ, Saxton JA (2015) Clinically Relevant Cognitive Impairment in Middle-Aged Adults With Childhood-Onset Type 1 Diabetes. Diabetes Care 38, 1768-1776.

15. Moryś JM, Kozera GM, Neubauer-Geryk J, Kruszewski P, Wolnik B, Nyka WM, Bieniaszewski L (2016) Statin Use and Cognitive Impairment in Patients With Type 1 Diabetes: an Observational Study. Clin Neuropharmacol 39, 182-187. 16. Lyoo IK, Yoon SJ, Musen G, Simonson DC, Weinger K, Bolo N, Ryan CM, Kim JE, Renshaw PF, Jacobson AM (2009) Altered prefrontal glutamate-glutamine-gammaaminobutyric acid levels and relation to low cognitive performance and depressive symptoms in type 1 diabetes mellitus. Arch Gen Psychiatry 66, 878-887.

17. Ryan CM, Geckle MO, Orchard TJ (2003) Cognitive efficiency declines over time in adults with Type 1 diabetes: effects of micro- and macrovascular complications.

Diabetologia 46, 940-948.

18. van Dijk M, Donga E, van Schie MK, Lammers GJ, van Zwet EW, Corssmit EP, Romijn JA, van Dijk JG (2014) Impaired sustained attention in adult patients with type 1 
diabetes is related to diabetes per se. Diabetes Metab Res Rev 30, 132-139.

19. Brands AM, Kessels RP, Hoogma RP, Henselmans JM, van der Beek Boter JW, Kappelle LJ, de Haan EH, Biessels GJ (2006) Cognitive performance, psychological well-being, and brain magnetic resonance imaging in older patients with type 1 diabetes. Diabetes 55, 1800-1806.

20. Barnea-Goraly N, Raman M, Mazaika P, Marzelli M, Hershey T, Weinzimer SA, Aye T, Buckingham B, Mauras N, White NH, Fox LA, Tansey M, Beck RW, Ruedy KJ, Kollman C, Cheng P, Reiss AL (2014) Alterations in white matter structure in young children with type 1 diabetes. Diabetes Care 37, 332-340.

21. Hannonen R, Komulainen J, Riikonen R, Ahonen T, Eklund K, Tolvanen A, Keskinen P, Nuuja A (2012) Academic skills in children with early-onset type 1 diabetes: the effects of diabetes-related risk factors. Dev Med Child Neurol 54, 457-463.

22. Marzelli MJ, Mazaika PK, Barnea-Goraly N, Hershey T, Tsalikian E, Tamborlane W, Mauras N, White NH, Buckingham B, Beck RW, Ruedy KJ, Kollman C, Cheng P, Reiss AL (2014) Neuroanatomical correlates of dysglycemia in young children with type 1 diabetes. Diabetes 63, 343-353.

23. Ferguson SC, Blane A, Wardlaw J, Frier BM, Perros P, McCrimmon RJ, Deary IJ (2005) Influence of an early-onset age of type 1 diabetes on cerebral structure and cognitive function. Diabetes Care 28, 1431-1437.

24. Prescott JH, Richardson JT, Gillespie CR (1990) Cognitive function in diabetes mellitus: the effects of duration of illness and glycaemic control.

Br J Clin Psychol 29,167-75.

25. Pańkowska E (2012) [The impact of dysglycemia on brain function in children with 
type 1 diabetes mellitus]. Med Wieku Rozwoj 16, 5-9.

26. Katz ML, Volkening LK, Anderson BJ, Laffel LM (2012) Contemporary rates of severe hypoglycaemia in youth with type 1 diabetes: variability by insulin regimen. Diabet Med 29, 926-932.

27. Davis EA, Soong SA, Byrne GC, Jones TW (1996) Acute hyperglycaemia impairs cognitive function in children with IDDM. J Pediatr Endocrinol Metab 9, 455-461.

28. Patiño-Fernández AM, Delamater AM, Applegate EB, Brady E, Eidson M, Nemery R, Gonzalez-Mendoza L, Richton S (2010) Neurocognitive functioning in preschool-age children with type 1 diabetes mellitus. Pediatr Diabetes 11, 424-430.

29. Cox DJ, Kovatchev BP, Gonder-Frederick LA, Summers KH, McCall A, Grimm KJ, Clarke WL (2005) Relationships between hyperglycemia and cognitive performance among adults with type 1 and type 2 diabetes. Diabetes Care 28, 71-77.

30. Hershey T, Perantie DC, Warren SL, Zimmerman EC, Sadler M, White NH (2005) Frequency and timing of severe hypoglycemia affects spatial memory in children with type 1 diabetes. Diabetes Care 28, 2372-2377.

31. Semenkovich K, Bischoff A, Doty T, Nelson S, Siller AF, Hershey T, Arbeláez AM. Clinical presentation and memory function in youth with type 1 diabetes. Pediatr Diabetes. 2015 Sep 17. doi: 10.1111/pedi.12314. [Epub ahead of print] 32. Musen G, Jacobson AM, Ryan CM, Cleary PA, Waberski BH, Weinger K, Dahms W, Bayless M, Silvers N, Harth J, White N (2008) Impact of diabetes and its treatment on cognitive function among adolescents who participated in the Diabetes Control and Complications Trial. Diabetes Care 31, 1933-1938. 
33. Jacobson AM, Musen G, Ryan CM, Silvers N, Cleary P, Waberski B, Burwood A, Weinger K, Bayless M, Dahms W, Harth J (2007) Long-term effect of diabetes and its treatment on cognitive function. N Engl J Med 356, 1842-1852.

34. McAulay V, Deary IJ, Sommerfield AJ, Frier BM (2006) Attentional functioning is impaired during acute hypoglycaemia in people with Type 1 diabetes. Diabet Med 23, 26-31.

35. Wright RJ, Frier BM, Deary IJ (2009) Effects of acute insulin-induced hypoglycemia on spatial abilities in adults with type 1 diabetes. Diabetes Care 32, 1503-1506.

36. Ewing FM, Deary IJ, McCrimmon RJ, Strachan MW, Frier BM (1998) Effect of acute hypoglycemia on visual information processing in adults with type 1 diabetes mellitus. Physiol Behav 64, 653-660.

37. Gonder-Frederick LA, Zrebiec JF, Bauchowitz AU, Ritterband LM, Magee JC, Cox DJ, Clarke WL (2009) Cognitive function is disrupted by both hypo- and hyperglycemia in school-aged children with type 1 diabetes: a field study. Diabetes Care 32, 10011006.

38. Speight J, Barendse SM, Singh H, Little SA, Rutter MK, Heller SR, Shaw JA (2014) Cognitive, behavioural and psychological barriers to the prevention of severe hypoglycaemia: A qualitative study of adults with type 1 diabetes. SAGE Open Med 2, 2050312114527443.

39. Frier BM (2011) Cognitive functioning in type 1 diabetes: the Diabetes Control and Complications Trial (DCCT) revisited. Diabetologia 54, 233-236.

40. Wysocki T, Harris MA, Mauras N, Fox L, Taylor A, Jackson SC, White NH (2003) Absence of adverse effects of severe hypoglycemia on cognitive function in school- 
aged children with diabetes over 18 months. Diabetes Care 26, 1100-1105.

41. Hannonen R, Tupola S, Ahonen T, Riikonen R (2003) Neurocognitive functioning in children with type-1 diabetes with and without episodes of severe hypoglycaemia. Dev Med Child Neurol 45, 262-268.

42. Strudwick SK, Carne C, Gardiner J, Foster JK, Davis EA, Jones TW (2005) Cognitive functioning in children with early onset type 1 diabetes and severe hypoglycemia. J Pediatr 147, 680-685.

43. Langan SJ, Deary IJ, Hepburn DA, Frier BM (1991) Cumulative cognitive impairment following recurrent severe hypoglycaemia in adult patients with insulintreated diabetes mellitus. Diabetologia 34, 337-344.

44. Wredling R, Levander S, Adamson U, Lins PE (1990) Permanentneuropsychological impairment after recurrent episodes of severe hypoglycaemia in man. Diabetologia 33, $152-157$.

45. Weinstock RS, DuBose SN, Bergenstal RM, Chaytor NS, Peterson C, Olson BA, Munshi MN, Perrin AJ, Miller KM, Beck RW, Liljenquist DR, Aleppo G, Buse JB, Kruger D, Bhargava A, Goland RS, Edelen RC, Pratley RE, Peters AL, Rodriguez H, Ahmann AJ, Lock JP, Garg SK, Rickels MR, Hirsch IB (2016) Risk Factors Associated With Severe Hypoglycemia in Older Adults With Type 1 Diabetes. Diabetes Care 39, 603610.

46. Hilmi A, Pasternak Y, Friger M, Loewenthal N, Haim A, Hershkovitz E (2013) Ethnic differences in glycemic control and diabetic ketoacidosis rate among children with diabetes mellitus type 1 in the Negev area. Isr Med Assoc J 15, 267-270. 47. Newfield RS, Cohen D, Capparelli EV, Shragg P (2009) Rapid weight gain in 
children soon after diagnosis of type 1 diabetes: is there room for concern? Pediatr Diabetes 10, 310-315.

48. Szypowska A, Ramotowska A, Grzechnik-Gryziak M, Szypowski W, Pasierb A, Piechowiak K. High Frequency of Diabetic Ketoacidosis in Children with Newly

Diagnosed Type 1 Diabetes. J Diabetes Res. 2016;2016:9582793. doi:

10.1155/2016/9582793. Epub 2015 Dec 13.

49. Al-Zubeidi H, Leon-Chi L, Newfield RS. Low vitamin $\mathrm{D}$ level in pediatric patients with new onset type 1 diabetes is common, especially if in ketoacidosis. Pediatr Diabetes. 2015 Dec 23. doi: 10.1111/pedi.12342. [Epub ahead of print]

50. Hong J, Jalaludin MY, Mohamad Adam B, Fuziah MZ, Wu LL, Rasat R, Fatimah H, Premaa S, Ponnudurai U, Jamaiyah H (2015) Diabetic ketoacidosis at diagnosis of type 1 diabetes mellitus in Malaysian children and adolescents. Malays Fam Physician 10, 11-18.

51. de Vries L, Oren L, Lebenthal Y, Shalitin S, Lazar L, Phillip M (2012) Decrease in frequency of ketoacidosis at diabetes onset over the past two decades - perspectives of a paediatric tertiary care centre. Diabet Med 29, e170-175.

52. Stipancic G, Sepec MP, Sabolic LL, Radica A, Skrabic V, Severinski S, Tiljak MK (2011) Clinical characteristics at presentation of type 1 diabetes mellitus in children younger than 15 years in Croatia. J Pediatr Endocrinol Metab 24, 665-670.

53. Neu A, Willasch A, Ehehalt S, Hub R, Ranke MB (2003) Ketoacidosis at onset of type 1 diabetes mellitus in children--frequency and clinical presentation. Pediatr Diabetes 4, 77-81.

54. Jessup AB, Grimley MB, Meyer E, Passmore GP, Belger A, Hoffman WH, Çalıkoğlu 
AS (2015) Effects of Diabetic Ketoacidosis on Visual and Verbal Neurocognitive Function in Young Patients Presenting with New-Onset Type 1 Diabetes. J Clin Res Pediatr Endocrinol 7, 203-210.

55. Cato MA, Mauras N, Mazaika P, Kollman C, Cheng P, Aye T, Ambrosino J, Beck RW, Ruedy KJ, Reiss AL, Tansey M, White NH, Hershey T (2016) Longitudinal Evaluation of Cognitive Functioning in Young Children with Type 1 Diabetes over 18 Months. J Int Neuropsychol Soc 22, 293-302.

56. Jacobson AM, Ryan CM, Cleary PA, Waberski BH, Weinger K, Musen G, Dahms W (2011) Biomedical risk factors for decreased cognitive functioning in type 1 diabetes: an 18 year follow-up of the Diabetes Control and Complications Trial (DCCT) cohort. Diabetologia 54, 245-255.

57. Ferguson SC, Blane A, Perros P, McCrimmon RJ, Best JJ, Wardlaw J, Deary IJ, Frier BM (2003) Cognitive ability and brain structure in type 1 diabetes: relation to microangiopathy and preceding severe hypoglycemia. Diabetes 52, 149-156. 58. van Duinkerken E, Klein M, Schoonenboom NS, Hoogma RP, Moll AC, Snoek FJ, Stam CJ, Diamant M (2009) Functional brain connectivity and neurocognitive functioning in patients with long-standing type 1 diabetes with and without microvascular complications: a magnetoencephalography study. Diabetes 58, 2335-2343.

59. Ryan CM, Williams TM, Finegold DN, Orchard TJ (1993) Cognitive dysfunction in adults with type 1 (insulin-dependent) diabetes mellitus of long duration: effects of recurrent hypoglycaemia and other chronic complications. Diabetologia 36, 329-334. 